\title{
Transposon-mediated generation of BCR-ABL1-expressing transgenic cell lines for unbiased sensitivity testing of tyrosine kinase inhibitors
}

\author{
Konstantin Byrgazovi, ${ }^{1,}$, Chantal Blanche Lucini ${ }^{1, *}$, Bettina Berkowitsch ${ }^{1}$, Margit \\ Koenig ${ }^{1}$, Oskar A. Haas ${ }^{1}$, Gregor Hoermann ${ }^{2}$, Peter Valent ${ }^{3}$, Thomas Lion ${ }^{1,4}$ \\ ${ }^{1}$ Children's Cancer Research Institute, Vienna, Austria \\ ${ }^{2}$ Department of Laboratory Medicine, Medical University of Vienna, Vienna, Austria \\ ${ }^{3}$ Department of Internal Medicine I, Division of Hematology \& Hemostaseology, Medical University of Vienna, Vienna, Austria \\ ${ }^{4}$ Department of Pediatrics, Medical University of Vienna, Austria \\ *These authors have contributed equally to this work \\ Correspondence to: Thomas Lion, email: thomas.lion@ccri.at \\ Keywords: BCR-ABL 1, tyrosine kinase inhibitors, Ba/F3, transposon-based gene transfer \\ Received: March 31, $2016 \quad$ Accepted: October 17, $2016 \quad$ Published: October 27, 2016
}

\section{ABSTRACT}

Point mutations in the ABL1 kinase domain are an important mechanism of resistance to tyrosine kinase inhibitors (TKI) in BCR-ABL1-positive and, as recently shown, $B C R-A B L 1$-like leukemias. The cell line Ba/F3 lentivirally transduced with mutant $B C R-A B L 1$ constructs is widely used for in vitro sensitivity testing and response prediction to tyrosine kinase inhibitors. The transposon-based Sleeping Beauty system presented offers several advantages over lentiviral transduction including the absence of biosafety issues, faster generation of transgenic cell lines, and greater efficacy in introducing large gene constructs. Nevertheless, both methods can mediate multiple insertions in the genome. Here we show that multiple BCR-ABL1 insertions result in elevated IC $_{50}$ levels for individual TKIs, thus overestimating the actual resistance of mutant subclones. We have therefore established flow-sorting-based fractionation of $B C R-A B L 1$-transformed $B a / F 3$ cells facilitating efficient enrichment of cells carrying single-site insertions, as demonstrated by FISH-analysis. Fractions of unselected $\mathrm{Ba} /$ F3 cells not only showed a greater number of BCR-ABL1 hybridization signals, but also revealed higher IC $_{50}$ values for the TKIs tested. The data presented highlight the need to carefully select transfected cells by flow-sorting, and to control the insertion numbers by FISH and real-time PCR to permit unbiased in vitro testing of drug resistance.

\section{INTRODUCTION}

The Philadelphia $(\mathrm{Ph})$ chromosome and the corresponding fusion gene $B C R-A B L 1$ are the genetic hallmarks of chronic myeloid leukemia (CML) and Phpositive acute lymphoblastic leukemia (Ph+ ALL) [1]. The BCR-ABL1 fusion gene [2], the alleged driver of the malignant phenotype in these leukemias, is known to activate several lines of downstream signaling including the MAP kinase, mTOR, JAK-STAT, and JAK-MYC pathways [3]. The introduction of imatinib and other TKIs has revolutionized the therapy of $\mathrm{Ph}+$ neoplasia $[4,5]$, and shows great promise in the treatment of $B C R$ - $A B L 1$-like leukemias involving deregulated tyrosine kinases $[6,7]$. In CML, most patients show good long-term responses to TKIs, but a considerable fraction eventually fail treatment and experience disease progression [8-11]. Clinical TKIresistance is most frequently associated with mutations in the tyrosine kinase domain (TKD) of the $B C R-A B L 1$ fusion gene $[12,13]$. The most commonly used model for in vitro sensitivity testing of novel TKIs and the prediction of resistance of emerging $B C R-A B L 1$ mutants [14-19] is the murine interleukin (IL)-3 dependent $\mathrm{Ba} / \mathrm{F} 3$ cell line, which can be rendered IL-3 independent by lentiviral (LV) transduction with the $B C R-A B L 1$ tyrosine kinase [20]. This system has also been widely used as a model for the 
discovery and characterization of other oncogenic tyrosine kinases [21]. Nevertheless, LV-mediated introduction of oncogenic kinases into $\mathrm{Ba} / \mathrm{F} 3$ cells has several relevant limitations and drawbacks. The transformation efficiency by LV transduction is rather low for large constructs due to the approximately 100-fold decreased success rate of RNA encapsidation into infectious particles for inserts over $6 \mathrm{~kb}$ in length [22], thus requiring laborious selection steps for the generation of transduced cell lines [23]. This problem also applies to full-length $B C R-A B L 1$ constructs which span over $5.8 \mathrm{~kb}$. Moreover, lentiviruses tend to insert within transcriptionally active sites, thereby increasing the risk of mutagenesis and altered gene expression [24-27]. Insertion of multiple copies of the construct within the genome, which is commonly mediated by LV transduction [25], can also result in elevated expression levels of the transduced gene. Additionally, cells carrying more than one copy of a gene construct with oncogenic properties may have a growth advantage in culture, thus possibly affecting the readout of ensuing analyses. The observation of rather variable inhibitory concentration $\left(\mathrm{IC}_{50}\right)$ values for individual TKIs reported for the same mutation in the BCR-ABL1 TKD might be attributable to this phenomenon [19, 28, 29]. Finally, the procedure of LV transduction can be very time consuming, and is associated with relevant biosafety issues. Based on these considerations, the Sleeping Beauty (SB) system, a synthetic DNA transposon designed to introduce defined DNA sequences into the chromosomes of vertebrate animals and humans, provides an attractive alternative for genetic transformation and insertional mutagenesis (Figure 1). The SB transposase targets TA-rich sites, preferentially the palindromic dinucleotide repeat ATATATATAT, in which the central TA is the canonical target site. In contrast to lentiviruses, there is no preference for coding or noncoding regions [30]. The SB system is a fast, simple and safe procedure for stable gene transfer facilitating efficient transfection even of large constructs [31-34]. However, similar to LV transduction, the SB system is also prone to generating multiple insertions in the genome which may be favored during the selection of engineered cells in culture $[30,35]$.

We have employed the SB system to establish $\mathrm{Ba} /$ F3 cell lines stably transfected with fluorescent proteins and $B C R-A B L 1$ constructs containing either wildtype $\left(B C R-A B L 1^{\mathrm{WT}}\right)$ or various mutants including $\mathrm{G} 250 \mathrm{E}$ $\left(B C R-A B L 1^{\mathrm{G} 250 \mathrm{E}}\right), \mathrm{E} 255 \mathrm{~V}\left(B C R-A B L 1^{\mathrm{E} 255 \mathrm{~V}}\right), \mathrm{T} 315 \mathrm{I}(B C R-$ $\left.A B L 1^{\mathrm{T} 315 \mathrm{I}}\right), \mathrm{F} 317 \mathrm{~L}\left(B C R-A B L 1^{\mathrm{F} 317 \mathrm{~L}}\right)$, and $\mathrm{F} 359 \mathrm{~V}(B C R-$ $\left.A B L 1^{\mathrm{F} 359 \mathrm{~V}}\right)$. Lentivirally transduced $\mathrm{Ba} / \mathrm{F} 3$ cell lines bearing the same BCR-ABL1 mutant constructs were tested for comparison. Fluorescence-activated cell sorting (FACS) with gating for low fluorescence was implemented to select cells displaying single gene construct insertions and homogenous transgene expression, and the efficacy of specific cell enrichment was documented by fluorescence in situ hybridization (FISH). The approach presented is applicable to cell line-based in vitro sensitivity testing of any mutation relevant in the clinical context, but was not designed for the monitoring of molecular remission or TKI resistance in patient samples. The data presented highlight the importance of using appropriately selected $\mathrm{Ba} / \mathrm{F} 3$ cells for clinically relevant readout of TKI sensitivity testing in vitro.

\section{RESULTS}

\section{Documentation of $B C R-A B L 1$ construct insertions by flow sorting and FISH analysis}

\author{
$\mathrm{Ba} / \mathrm{F} 3$ cells carrying $B C R-A B L 1^{\mathrm{wT}}, B C R-A B L 1^{\mathrm{G} 250 \mathrm{E}}$,
} $B C R-A B L 1^{\mathrm{E} 255 \mathrm{~V}}, \quad B C R-A B L 1^{\mathrm{T} 315 \mathrm{I}}, \quad B C R-A B L 1^{\mathrm{F} 317 \mathrm{~L} / \mathrm{V}}$ or $B C R-A B L 1^{\mathrm{F} 359 \mathrm{~V}}$ constructs were generated either by SB- or by LV-mediated gene transfer. After selection of successfully transformed cells using a fluorescence protein marker and IL-3 depletion, cells were either sorted for low fluorescence, as displayed in Figure 2A and Supplementary Figure S1, or remained unsorted. Both flow-sorted and unselected cell fractions were subjected to FISH analysis in order to assess the number of construct insertions in the genome. While 92-97\% of cells obtained by low fluorescence-based flowsorting showed single hybridization signals (Figure 2B, Supplementary Table S2), up to $67 \%$ of cells from the unselected fraction displayed two or more signals (Figure 2A, Supplementary Table S2). Flow cytometry-based analysis of the transformed cells displayed different types of fluorescence distribution (Figure 3). All LV-transduced $\mathrm{Ba} / \mathrm{F} 3$ cells displayed a double peak, as presented in Figure 3A and Supplementary Figure S1, whereas SBmediated transfection yielded three different types of peaks prior to selection. The analysis of unselected cells by FISH showed that the peak shape reflects the proportion of cells with multiple gene construct insertions (Supplementary Table S2). A double peak indicating a very high percentage of cells carrying an elevated number of insertions was observed in unselected $\mathrm{Ba} / \mathrm{F} 3$ cells with $B C R-A B L 1^{\text {WT }}$ (Figure $3 \mathrm{~A}$ ). A broad peak resulting from a lower but still relevant number of cells with more than one insertion was detected in $\mathrm{Ba} / \mathrm{F} 3$ cells with $B C R-A B L 1^{\mathrm{T} 315 \mathrm{I}}$ and $B C R-A B L 1^{\mathrm{F} 317 \mathrm{~L}}$ (Figure $3 \mathrm{~B}$ ). Finally, unselected $\mathrm{Ba} /$ $\mathrm{F} 3$ cells with $B C R-A B L 1^{\mathrm{G} 250 \mathrm{E}}, B C R-A B L 1^{\mathrm{E} 255 \mathrm{~V}}$ and $B C R-$ $A B L 1^{\mathrm{F} 359 \mathrm{~V}}$ revealed a slender peak revealing the presence of single construct insertions in the vast majority of cells (Figure 3C), indicating that further selection by flowsorting for downstream analyses may not be required.

\section{$B C R-A B L 1$ expression levels in $\mathrm{Ba} / \mathrm{F} 3$ cells with single and multiple construct insertions}

The increased copy number of $B C R-A B L 1$ insertions in unselected cell fractions displaying broad or double peaks in flow-cytometric analysis was also 
confirmed by quantitative PCR investigation of genomic DNA isolated from cells before flow-sorting. While most flow-sorted cells displayed a single copy of $B C R-A B L 1$ inserts per diploid genome, unselected cells revealed a significantly higher average number of $B C R-A B L 1$ insertions (Figure 4A and Supplementary Figure S2A). Real-time RT-PCR analysis indicated that flow-sorted cells carrying single insertions of the construct provide

A

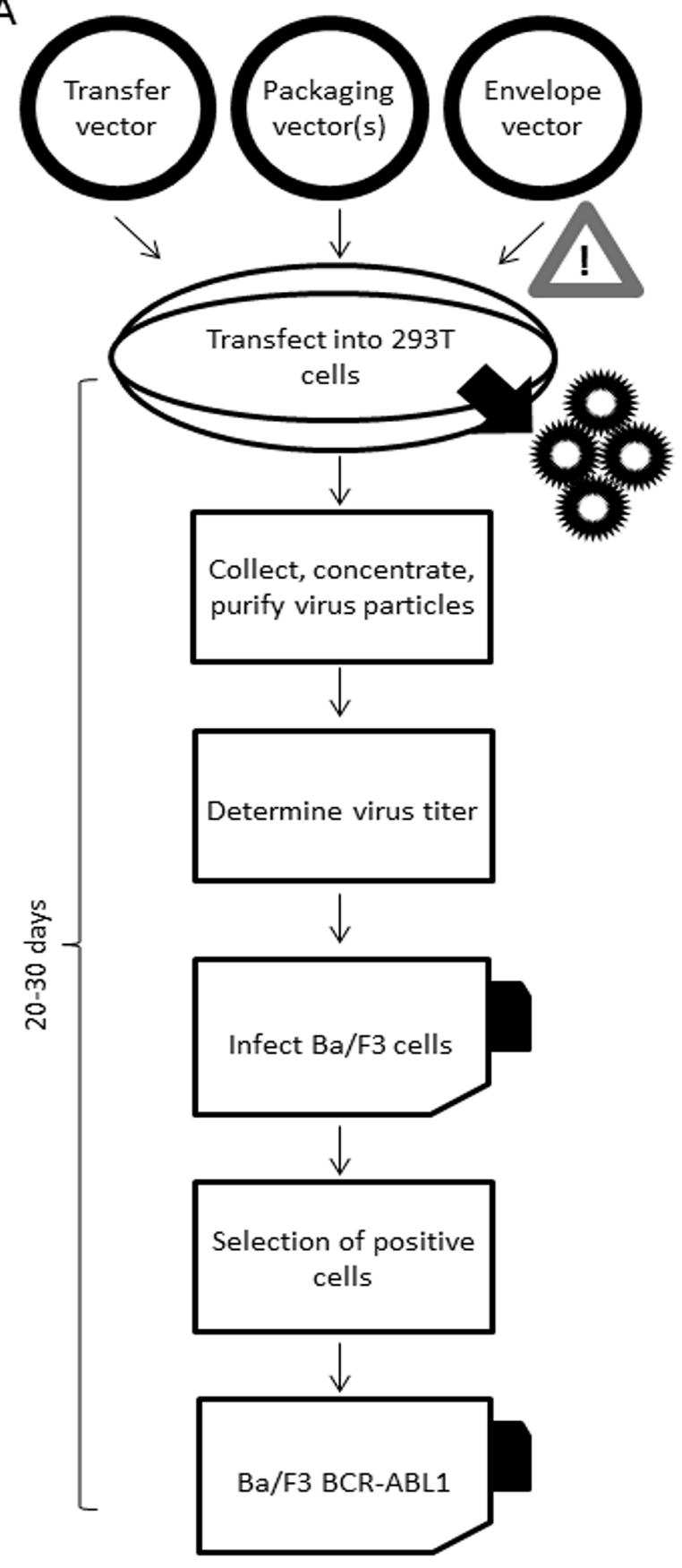

uniform mRNA expression levels in all transfected cell lines tested (Figure 4B and Supplementary Figure $\mathrm{S} 2 \mathrm{~B})$. Moreover, $B C R-A B L 1$ expression in these cells corresponded to the levels detectable in clinical specimens of patients in chronic phase of CML, based on the experience of our European LeukemiaNet (ELN)certified reference laboratory. By contrast, unselected $\mathrm{Ba} / \mathrm{F} 3$ cells (with the exception of those revealing

B

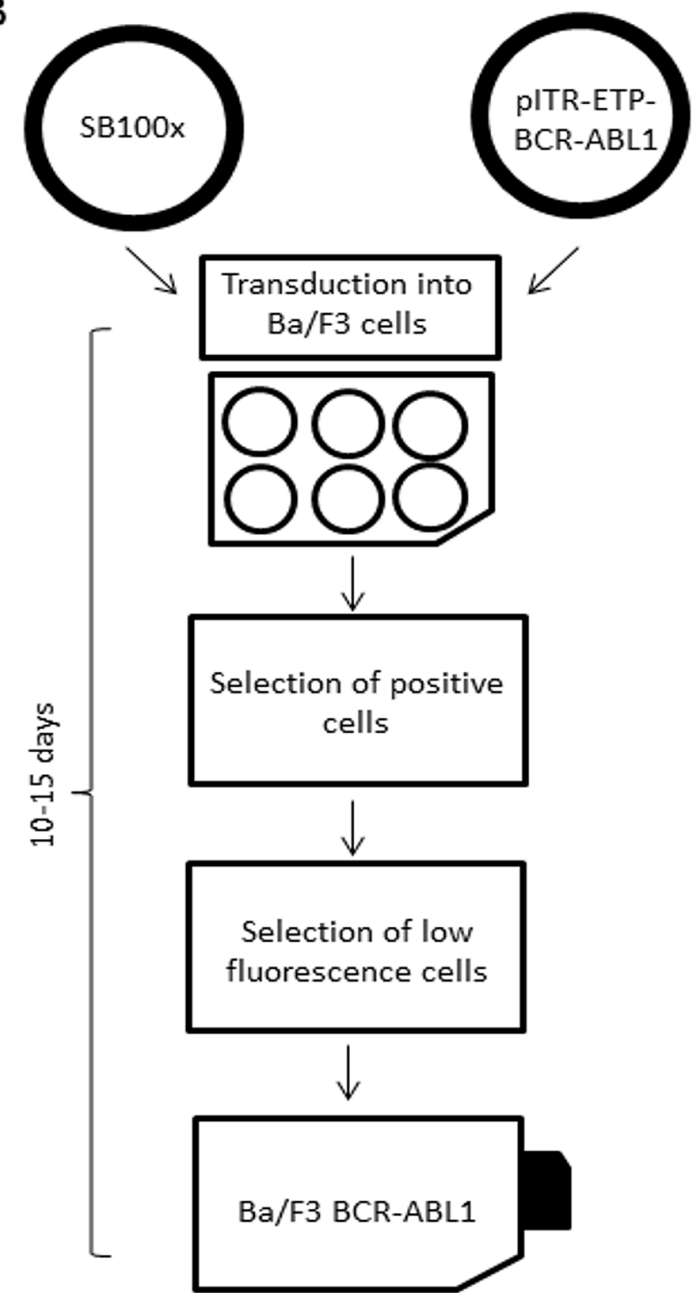

Figure 1: Workflows of lentiviral A. and Sleeping Beauty transposon-based B. transformation of Ba/F3 cells with $B C R$ $A B L 1$ fusion gene constructs. 
A
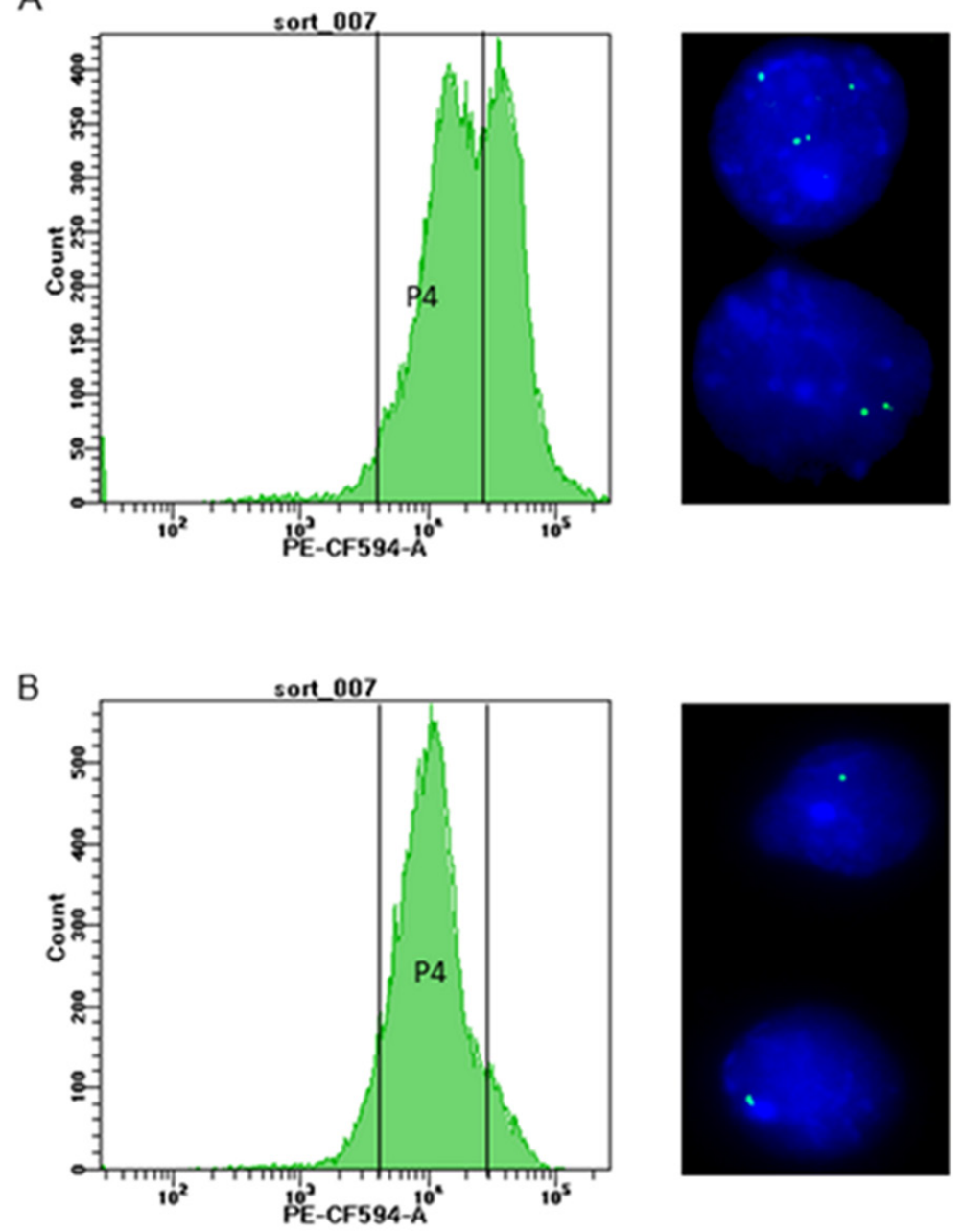

Figure 2: Flow-sorting of Ba/F3 cells. Panel A. shows the histogram before sorting, with gate P4 encompassing a low-fluorescent cell fraction for targeted enrichment. Gate P4 was set above the auto-fluorescence level of Ba/F3 cells (4 x $10^{3}$ PE-CF594 -A fluorescence on the FACSAriaFusion instrument) and $2 \times 10^{4}$ PE-CF594. On the right, the FISH image taken before flow-sorting documents the unsorted cells with two or more insertions (630x magnification). Panel B. shows the histogram of flow-sorted cells after one week in cell culture, with the great majority of cells located within gate P4. The FISH image on the right documents selective enrichment of cells carrying single insertions of $B C R-A B L 1$ constructs by gating for cells with appropriate fluorescence intensity.
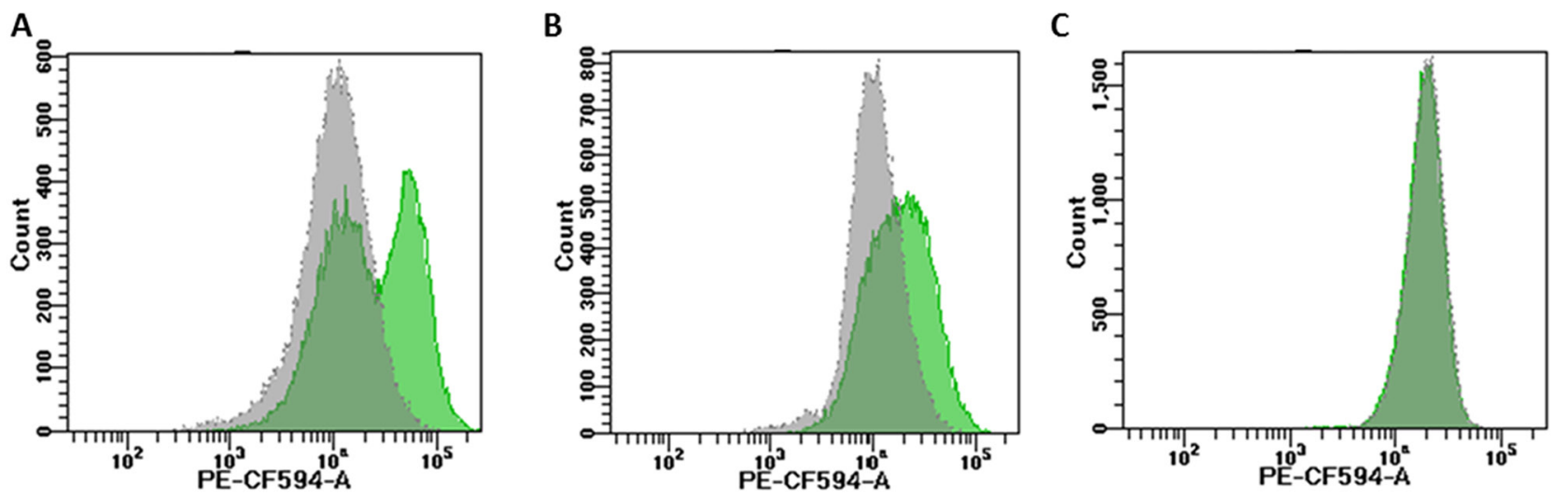

Figure 3: Different types of fluorescence distribution in unselected cells. Unselected Ba/F3 cells carrying various BCR-ABL1 constructs displayed three types of the fluorescence distribution in flow-cytometry histograms: double peak Panel A. broad peak Panel B. and slender peak Panel C. The green histograms reflect unselected cells, and the changes after appropriate flow-sorting are shown in grey. 
slender peaks upon flow-cytometry) revealed variable and significantly higher $B C R-A B L 1$ expression levels, apparently reflecting the predominant number of genomic insertions of the construct.

\section{Impact of the number of $B C R-A B L 1$ insertions on TKI responsiveness in vitro}

Both unselected and flow-sorted $\mathrm{Ba} / \mathrm{F} 3$ cells with wildtype or mutant $B C R-A B L 1$ constructs introduced either by SB-assisted transfection or LV-mediated transduction were subjected to in vitro survival assays with increasing concentrations of nilotinib, dasatinib, and ponatinib. The $\mathrm{IC}_{50}$ values obtained are displayed in Table 1 and Supplementary Table S3. Cells isolated by flow-sorting according to low fluorescence levels (Figure 2A) revealed $\mathrm{IC}_{50}$ values corresponding to the lowest measurements published previously [19, 36] while unselected cells displaying broad or double peaks at flow-cytometric analysis showed considerably higher values often indicating resistance to the TKI tested. In unselected $B C R-A B L 1^{\mathrm{T} 315 \mathrm{I}} \mathrm{LV}$-transduced $\mathrm{Ba} / \mathrm{F} 3$ cells which displayed multiple insertions of the construct, as documented by FISH analysis (Supplementary Table S2), the $\mathrm{IC}_{50}$ determined was $35 \mathrm{nM}$ (Supplementary Table S2), a value considerably higher than reported previously, and exceeding the effective plasma concentration of ponatinib achievable in the clinical setting with $45 \mathrm{mg}$ per day [28]. Similar observations were also made in unselected $\mathrm{Ba} / \mathrm{F} 3$ cells carrying other $B C R-A B L 1$ constructs and displaying broad or double peaks in FACS histograms, where the $\mathrm{IC}_{50}$ values correlated with the predominant number of insertions (Table 1) and (Supplementary Table S3).



Figure 4: Real time PCR analysis of the copy number inserts and BCR-ABL1 expression analysis. Panel A. shows the copy number of $B C R-A B L 1$ inserts in the diploid genome of $\mathrm{Ba} / \mathrm{F} 3$ cells before (dark grey bars) and after (light grey bars) flow-sorting. Panel B. shows the relative expression levels of $B C R-A B L 1$ before (dark grey bars) and after (light grey bars) sorting. The dashed horizontal line highlights the average of one $B C R-A B L 1$ construct insertion in flow-sorted cells and the uniform $B C R$ - $A B L 1 \mathrm{mRNA}$ expression level in flow-sorted cells uns, unselected; fl-s, flow-sorted; ** $\mathrm{p}<0.01 ; * * * \mathrm{p}<0.001 ; * * * * \mathrm{p}<0.0001$. 
Table 1: Analysis of in vitro response to different tyrosine kinase inhibitors.

\begin{tabular}{lccc}
\hline & IC $_{\text {50 }}$ values of unselected and flow-sorted Ba/F3-SB-BCR-ABL1 (nM) & \\
\hline BCR-ABL1 variant & Nilotinib & Dasatinib & Ponatinib \\
\hline WT unselected & $25.0 \pm 6.0$ & $4.2 \pm 1.3$ & $10.0 \pm 2.0$ \\
WT flow-sorted & $10.0 \pm 3$ & $2.3 \pm 1.2$ & $2.1 \pm 0.8$ \\
$p$-value & $\leq 0.001$ & $\leq 0.05$ & $\leq 0.001$ \\
G250E unselected & $65.0 \pm 15.0$ & $10.0 \pm 2.0$ & $12.0 \pm 2.0$ \\
G250E flow-sorted & $50.0 \pm 10.0$ & $2.2 \pm 0.5$ & $5.7 \pm 1.6$ \\
$p$-value & $\leq 0.01$ & $\leq 0.001$ & $\leq 0.001$ \\
E255V unselected & $1000.0 \pm 150.0$ & $11.0 \pm 2.0$ & $12.5 \pm 1.5$ \\
E255V flow-sorted & $900.0 \pm 120.0$ & $10.0 \pm 1.5$ & $10.5 \pm 1.8$ \\
$p$-value & $\leq 0.1$ & 0.18 & $\leq 0.1$ \\
T315I unselected & $9000 \pm 1500$ & $>10000$ & $30.0 \pm 5.0$ \\
T315I flow-sorted & $7500 \pm 1400$ & $>10000$ & $10.0 \pm 2.0$ \\
$p$-value & $\leq 0.05$ & $N A$ & $\leq 0.001$ \\
F359V unselected & $67.0 \pm 15.0$ & $2.7 \pm 1.2$ & $6.5 \pm 1.6$ \\
F359V flow-sorted & $60.0 \pm 12.0$ & $2.5 \pm 1.1$ & $6.0 \pm 1.3$ \\
$p$-value & 0.22 & 0.67 & 0.41 \\
F317L unselected & $120.0 \pm 20.0$ & $20.0 \pm 3.0$ & $8.6 \pm 2.7$ \\
F317L flow-sorted & $54.0 \pm 12.0$ & $8.3 \pm 2.6$ & $2.5 \pm 1.1$ \\
$p$-value & $\leq 0.001$ & $\leq 0.001$ & $\leq 0.001$ \\
\hline
\end{tabular}

The indicated $\mathrm{IC}_{50}$ values were determined in unselected and low-fluorescent flow-sorted $\mathrm{Ba} / \mathrm{F} 3$ cells carrying wildtype or different mutant $B C R-A B L 1$ constructs introduced by Sleeping Beauty (SB) transposon-mediated transfer. NA, not applicable.

\section{Kinase activity and proliferation of $\mathrm{Ba} / \mathrm{F} 3$ cells with single and multiple insertions of $B C R-A B L 1$}

Western blot analysis was performed to compare the impact of single and multiple $B C R-A B L 1$ constructs in $\mathrm{Ba} / \mathrm{F} 3$ cells on the ABL1 kinase activity and its downstream signaling by assessing phosphorylation of the target proteins Crkl, Gab2, and Akt [37, 38]. In comparison to flow-sorted cells displaying lowfluorescence (Figure 5, lanes 3, 9, and 11), unselected cells (Figure 5, lanes 2, 8, and 10) revealed elevated phosphorylation levels of the downstream proteins tested, unless the peaks of flow-cytometric analysis were slender (Figure 5, lanes 4, 5, 6, 7, 12, and 13). The unselected LV-transduced cells, all displaying a double peak, likewise reveal higher phosphorylation of the important downstream proteins in comparison to the flow-sorted cells (Supplementary Figure S3). The data indicate that the presence of two or more $B C R-A B L 1$ construct insertions in a high proportion of the cells investigated correlates with increased kinase activity.

In order to assess whether cells with multiple insertions have a proliferative advantage, unselected $\mathrm{Ba} / \mathrm{F} 3$ cells with $B C R-A B L 1^{\mathrm{T} 315 \mathrm{I}}$ (Figure 6A) and $B C R-A B L 1^{\mathrm{F} 317 \mathrm{~L}}$ (Figure 6B) constructs previously shown by FISH analysis to represent a mixture of populations with one, two and more insertions were investigated. The cells were grown in culture under standard conditions to study their proliferative behavior. After four weeks in culture, the cells were subjected to FACS analysis and the histograms revealed a major shift towards higher fluorescence levels. Subsequent assessment by FISH analysis showed multiple hybridization signals in virtually all cells analyzed (Supplementary Table S4) indicating the proliferative advantage of cells with several insertions of $B C R-A B L 1$ constructs.

\section{DISCUSSION}

The importance of point mutations in the TKD of the $B C R-A B L 1$ fusion gene as a mechanism of TKI resistance has rendered in vitro sensitivity testing of emerging $B C R$ $A B L 1$ mutants a highly relevant diagnostic technique supporting clinical decisions [14-19, 29, 39]. The most commonly used approach to TKI sensitivity testing is based on exploitation of the murine $\mathrm{Ba} / \mathrm{F} 3$ cell line carrying mutant $B C R-A B L 1$ constructs introduced by LV- 


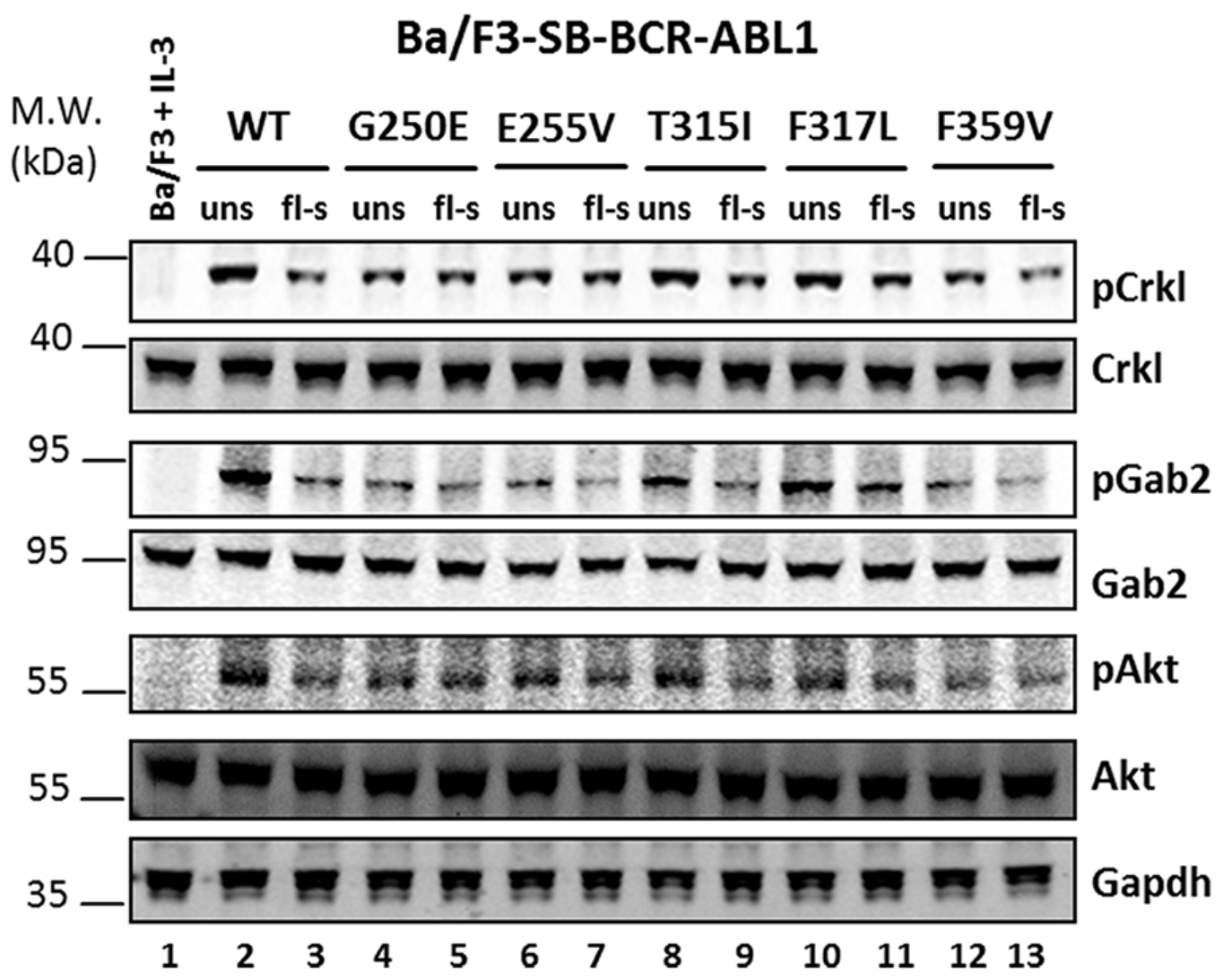

Figure 5: Western blot analysis of unselected and flow-sorted Ba/F3-BCR-ABL1 cells. Cell lysates were prepared from the parental $\mathrm{Ba} / \mathrm{F} 3$ cells (growing in the presence of IL-3) (lane 1) and $\mathrm{Ba} / \mathrm{F} 3$ cells bearing different $B C R-A B L 1$ constructs before and after flow-sorting, as indicated in Figure 2. The cell lysates were probed against different antibodies targeting the proteins indicated on the right. WT, wildtype; uns, unselected cells; fl-s, flow-sorted cells.

A

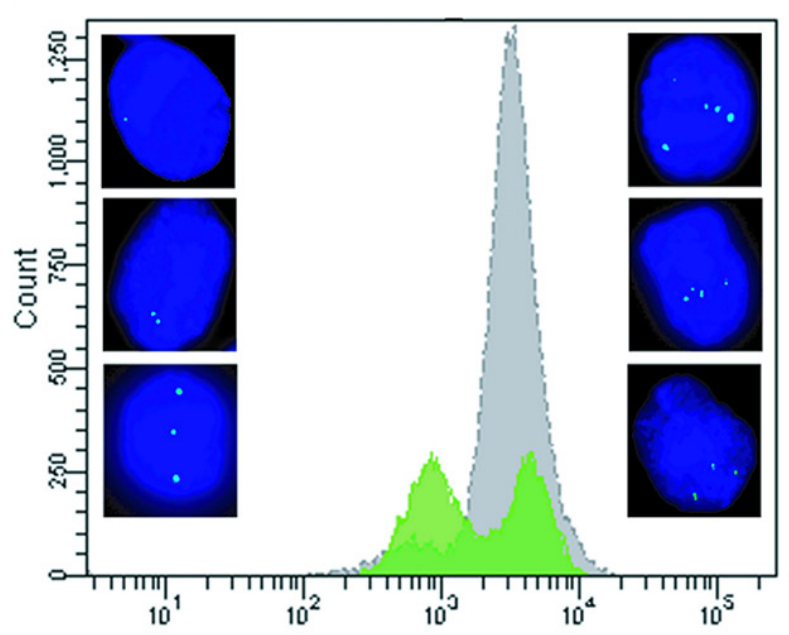

$\mathrm{B}$

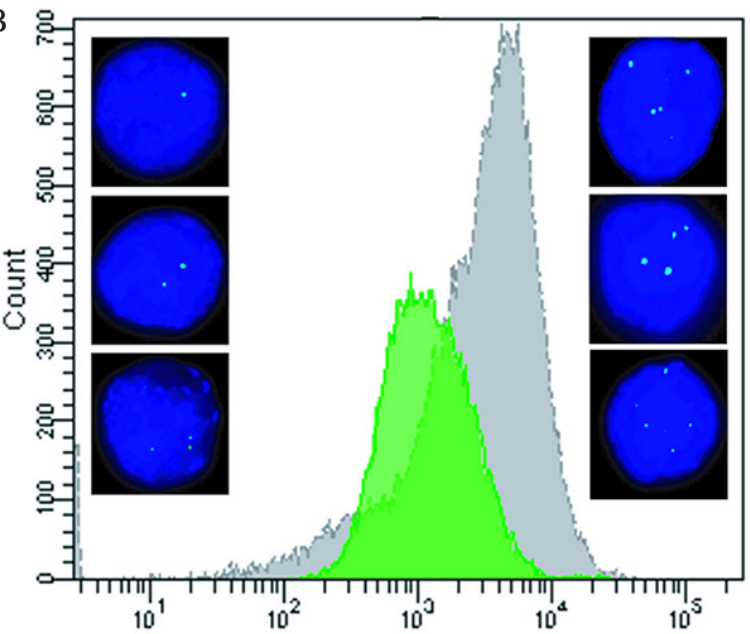

Figure 6: Outgrowth of cells with multiple BCR-ABL1 construct insertions in culture. Panel A. Unselected Ba/F3 cells SBtransfected with $B C R-A B L 1^{\mathrm{T31} 15 \mathrm{l}}$ before and after expansion in cell culture for four weeks. Prior to culturing, the histogram of FACS-analysis revealed two peaks with different fluorescence intensities (green), and FISH-analysis indicated the presence of cells with 1-3 insertion sites of the $B C R-A B L I^{\mathrm{T} 315 \mathrm{I}}$ construct (left side of the panel). After four weeks in culture, outgrowth of cells with higher fluorescence levels was evident (grey peak), and FISH-analysis showed predominance of cells with multiple insertion signals (right side of the panel). Panel B. Unselected $\mathrm{Ba} / \mathrm{F} 3$ cells SB-transfected with $B C R-A B L 1^{\mathrm{F} 317 \mathrm{~L}}$ revealing identical findings, i.e. outgrowth of cells with multiple insertions of the construct during cell culture. 
mediated transduction [20]. Here we present an alternative technique, the transposon-based SB system, which offers advantages with regard to efficacy, speed, and safety [3234, 40]. Nevertheless, we have demonstrated that both technical approaches can lead to multiple insertions of $B C R-A B L 1$ gene constructs which result in artificially elevated $\mathrm{IC}_{50}$ values for the TKIs tested. Reports indicating variable $\mathrm{IC}_{50}$ values for different TKIs tested against individual $B C R-A B L 1$ mutants might be attributable to this phenomenon. This is exemplified by published $\mathrm{IC}_{50}$ values for ponatinib against the P-loop mutation E255V including $16 \mathrm{nM}$ [28], $33 \mathrm{nM}$ [29], and even $56 \mathrm{nM}$ [19]. The latter two values are beyond the achievable effective plasma concentration of the drug [28], and therefore indicate resistance. Such observations including the data presented underline the importance of generating $\mathrm{Ba} / \mathrm{F} 3$ cells with single insertions of mutant $B C R-A B L 1$ constructs to provide a basis for adequate in vitro sensitivity testing of TKIs. Here we demonstrate that this goal is readily achievable by flow-sorting of SB-transfected $\mathrm{Ba} / \mathrm{F} 3$ cells with gating for cell fractions with defined low fluorescence levels. The flow-sorting step does not seem to be required if the flow-cytometry histograms reveal a narrow peak indicating great predominance of cells with single insertions of the respective construct. While narrow peaks were observed in half of the cell preparations using the SB-transfection system, they did not occur in any of the preparations based on LV-transduction. Unselected preparations displaying broad or double peaks in flowcytometry histograms were shown to contain relevant proportions of $\mathrm{Ba} / \mathrm{F} 3$ cells with multiple $B C R-A B L 1$ construct insertions which resulted in artificially increased $\mathrm{IC}_{50}$ values for the TKIs tested. Moreover, the expansion of unselected $B C R-A B L 1$-transformed $\mathrm{Ba} / \mathrm{F} 3$ cells in culture was shown to favor proliferation and outgrowth of cells with multiple insertions, thereby preventing adequate in vitro sensitivity testing. The observation of greatly elevated $\mathrm{IC}_{50}$ values in these instances is in line with reports on amplification of the $B C R-A B L 1$ fusion gene as a relevant mechanism of resistance to kinase inhibitors [41-43]. Our data also revealed that multiple insertions correlate with enhanced kinase activity of BCR-ABL1 resulting in increased phosphorylation of the adaptor proteins Crkl and Gab2, which are prominent downstream targets implicated in leukemogenesis of $\mathrm{Ph}+$ neoplasia [38]. Moreover, the mTOR signaling pathway was also upregulated in unselected cells, as demonstrated by elevated levels of phosphorylated Akt.

The generation of multiple gene construct insertions in $\mathrm{Ba} / \mathrm{F} 3$ cells by $\mathrm{LV}$ - or transposon-mediated transfer has not been reported previously as a relevant problem in the context of in vitro drug sensitivity testing. Our data demonstrate that targeted flow-sorting of low-fluorescent $B C R-A B L 1$-transformed $\mathrm{Ba} / \mathrm{F} 3$ cells facilitates enrichment of virtually pure cell fractions carrying single insertions of the gene construct. Employment of this selection step is highly recommended for all cell preparations displaying broad or double peaks in flow-cytometry histograms to permit unbiased in vitro testing of drug resistance. The clinical relevance of our observations has far reaching consequences beyond $\mathrm{Ph}+$ neoplasia. The rapidly increasing number of reports on $B C R-A B L 1$ like leukemias involving a variety of activated kinases highlights the relevance of TKI-based treatment and in vitro prediction of sensitivity to these agents $[6,7,44]$. Appropriate modeling of activated and/or mutant kinases inserted at single sites into $\mathrm{Ba} / \mathrm{F} 3$ cells, as presented in this report, is therefore of paramount importance for reliable prediction of treatment responses to kinase inhibitors in vitro, and opens improved possibilities for patient care in the growing field of precision medicine and targeted treatments.

\section{MATERIALS AND METHODS}

\section{Cloning of $B C R-A B L 1$ into pITR-ETP SB vector}

The full-length coding sequence of $B C R-A B L 1$ was amplified from cDNA of the K-562 cell line using the primers BCR_pITR_FW and ABL_pITR_RV (Supplementary Table S1) and cloned into Sfil-linearized pITR-ETP vector containing genes for puromycin resistance and the fluorescent protein tdTomato [33, 34, 40] using the In-Fusion Kit (Clontech Laboratories, Mountain View, CA, USA). The resulting plasmid pITR-ETP-BCR-ABL $1^{\text {WT }}$ was subjected to site-directed mutagenesis using the complementary primer pairs G250E_s/G250E_as. E255V_s/E255V_as, T315I_s/ T315I_as, and F317L_s/ F317 as (Supplementary Tab̄e S1) by implementing the QuikChange II XL Kit (Agilent Technologies, Santa Clara, CA, USA) according to the manufacturer's recommendations. Following targeted mutagenesis, the $4 \mathrm{~kb}$ fragments including the $B C R$ $A B L 1$ TKD sequence between the SalI and SgrAI sites on each plasmid were sequenced and subcloned back into the pITR-ETP-BCR-ABL $1^{\mathrm{WT}}$ template to ensure that no passenger mutations have been introduced.

\section{Generation of $B C R-A B L 1$-expressing $B a / F 3$ cells and selection by flow-sorting}

The murine cell line $\mathrm{Ba} / \mathrm{F} 3$ was obtained from DSMZ (Braunschweig, Germany, June, 2015) where the cells are authenticated using PCR-based methods. Ba/ F3 were maintained in RPMI 1640 medium (Thermo Fisher Scientific, Waltham, MA, USA) containing $10 \%$ fetal bovine serum (Thermo Fisher Scientific), $1 \%$ penicillin-streptomycin (Thermo Fisher Scientific) and supplemented with $2 \mathrm{ng} / \mathrm{ml}$ murine IL-3 (SigmaAldrich, St. Louis, MO, USA). Cells were seeded at $3 \mathrm{x}$ $10^{5}$ cells $/ \mathrm{ml}$ and kept at a density below $1.5 \times 10^{6}$ cells/ ml. Nucleofection of pITR-ETP-BCR-ABL1 plasmids 
and transposase-encoding vector pcGlobin100x, using $4 \mu \mathrm{g}$ and $1 \mu \mathrm{g}$, respectively, was performed using Cell Line Nucleofector ${ }^{\circledR}$ Kit V (Lonza, Basel, Switzerland) according to the manufacturer's instructions. Puromycin (Sigma-Aldrich) was added at $1 \mu \mathrm{g} / \mathrm{ml}$ to the medium 24 $\mathrm{h}$ after transfection, followed by selection for 2-5 days. All cells positive for the fluorescent protein tdTomato were isolated by flow-sorting using the FACSAriaFusion instrument (BD Bioscience,Franklin Lakes, NJ, USA) and grown in IL-3-containing medium to a density of $0.8-1 \times 10^{6}$ cells $/ \mathrm{ml}$. IL-3-independent growth was assessed by washing the cells three times with IL-3-free medium followed by expansion in IL-3-free medium to $0.8-1 \times 10^{6} / \mathrm{ml}$. Finally, the cells were either left unsorted or enriched according to a defined low-fluorescence range (Figure 2A), and used for further experiments immediately after recovery. Fluorescence of sorted cells was controlled one week after sorting to assess the homogeneity of the cell population. For the unsorted $B C R-A B L 1$ mutant cells displaying T315I or F317L, the changes in fluorescence were measured after one month in culture. LV-transduced Ba/F3 cells [45] employed for control purposes were maintained in IL3-free medium and tested in parallel with SB-transfected cells in different experiments.

\section{Fluorescence in situ hybridization}

The analysis by FISH was performed essentially as described [46]. Briefly, a digoxigenin-12-dUTP labelled pITR-ETP-BCR-ABL1 plasmid was used as hybridization probe to determine the number of $B C R-A B L 1$ construct insertions in the genome. Sheep antidigoxigeninfluorescein isothiocyanate 1:100 (Roche Diagnostics, Basel, Switzerland) was used for immunodetection of hybridized probes. Signals were analyzed using a ZEISS Imager M2 fluorescence microscope (Carl Zeiss, Jena, Germany) and the Genesis software (Applied Spectral Imaging, Carlsbad, CA, USA).

\section{Tyrosine kinase inhibitor sensitivity assays}

The TKIs nilotinib, dasatinib and ponatinib (all from Selleckchem, Houston, TX, USA) were obtained as 10 $\mathrm{mM}$ stocks in DMSO. Imatinib was not included because of its restricted efficacy in the presence of mutations. Serial TKI dilutions were prepared in phenol red-free RPMI 1640 containing 10\% fetal bovine serum, and $1 \%$ penicillin-streptomycin, (Thermo Fisher Scientific) for subsequent in vitro sensitivity assays. $B C R-A B L 1$ expressing $\mathrm{Ba} / \mathrm{F} 3$ cells were seeded in 96-well plates at $3 \times 10^{5}$ cells $/ \mathrm{ml}$ and incubated with the respective TKI for $72 \mathrm{~h}$ at $37^{\circ} \mathrm{C} / 5 \% \mathrm{CO}_{2}$. Survival was assessed using the Vybrant ${ }^{\circledR}$ MTT Cell Proliferation Assay Kit (Thermo Fisher Scientific) according to a protocol provided by the manufacturer. To estimate the $\mathrm{IC}_{50}$ of individual drugs for wildtype and mutant cells, smoothed dose-response curves were fitted using OriginPro 6.1 software (OriginLab, Northampton, MA, USA). The $\mathrm{IC}_{50}$ values were calculated by determining the mean of three independent experiments each performed in quadruplicates.

\section{Immunoblotting}

A total of $15 \times 10^{6} \mathrm{Ba} / \mathrm{F} 3$ cells SB-transfected or LVtransduced with $B C R-A B L 1$ were lysed using high-salt buffer $(20 \mathrm{mM}$ Tris* $\mathrm{HCl}, 400 \mathrm{mM} \mathrm{NaCl}, 0.5 \%$ NP40, $0.3 \%$ Triton X100) with Halt protease and phosphatase inhibitor cocktail (Thermo Fisher Scientific). The protein content was assessed using the Bio-Rad Protein Assay Kit II (Bio-Rad, Hercules, CA, USA). After denaturing the samples in NuPAGE ${ }^{\circledR}$ LDS Sample Buffer (Thermo Fisher Scientific), proteins were separated by electrophoresis using NuPAGE ${ }^{\circledR}$ 4-12\% Bis-Tris Protein Gels (Thermo Fisher Scientific), transferred onto PVDF membranes (Thermo Fisher Scientific) with the XCell II ${ }^{\mathrm{TM}}$ Blot Module (Thermo Fisher Scientific), and treated with Odyssey Blocking Buffer TBS (LI-COR, Lincoln, NE, USA). Antibodies directed against the following targets were used to probe the membranes: phospho-Akt (Ser473), phospho-Gab2 (Tyr452), phospho-Crkl (Tyr207), Akt, Gab2, Crk1 (all from Cell Signaling Technology, Danvers, MA, USA) and GAPDH (Abcam, Cambridge, UK). The DyLight ${ }^{\mathrm{TM}}$ conjugated antibodies (Cell Signaling Technology) were used for visualization of specific bands.

\section{Quantitative real-time PCR analysis}

Genomic DNA was isolated using the DNeasy Blood and Tissue Kit (QIAGEN). Total RNA was isolated with the help of RNeasy Plus Mini Kit (QIAGEN) and reversetranscribed by employing the High Capacity cDNA Synthesis Kit (Thermo Fisher Scientific). The number of $B C R-A B L 1$ double- or single-stranded DNA molecules was quantified on the Taqman 7500 Real Time PCR System (Thermo Fisher Scientific) using the primer probe set Hs03024784_ft (Thermo Fisher Scientific). Taqman mouse copy number reference assays Trfe and Tert (Thermo Fisher Scientific) were used for normalization of the number of $B C R-A B L 1$ inserts into the murine genome. The primer/probe set Mm01197698_m1 recognizing murine Gusb transcripts was used for normalization of the number of $B C R-A B L 1$ transcripts. All experiments were done twice in triplicates. The standard curves were built using the plasmids pITR-ETP-BCR-ABL1 ${ }^{\text {wT }}$, pCMV6Gusb (Origene) and mouse genomic DNA (Promega). Relative expression levels and copy number variations were calculated according to the $\Delta \Delta \mathrm{Ct}$ method.

\section{Statistical analysis}

In the experiments described, two independent samples were analyzed in triplicates, unless indicated 
otherwise. Statistical analysis was performed using the OriginPro 6.1 software (OriginLab), and the two-sample independent T-test was employed for the calculation of significance values.

\section{ACKNOWLEDGMENTS}

We thank Sabine Strehl and Dagmar Schinnerl for valuable input and fruitful discussions.

\section{CONFLICTS OF INTEREST}

The authors declare no relevant conflict of interest.

\section{GRANT SUPPORT}

This work was supported by the Austrian Science Fund (FWF), SFB Grants F4705-B20 to Thomas Lion and F4704-B20 to Peter Valent.

\section{REFERENCES}

1. Nowell PC, Hungerford DA. Chromosome studies in human leukemia. II. Chronic granulocytic leukemia. J Natl Cancer Inst. 1961; 27: 1013-35.

2. Groffen J, Stephenson JR, Heisterkamp N, de Klein A, Bartram CR, Grosveld G. Philadelphia chromosomal breakpoints are clustered within a limited region, bcr, on chromosome 22. Cell. 1984; 36: 93-9.

3. Hantschel O. Structure, regulation, signaling, and targeting of abl kinases in cancer. Genes Cancer. 2012; 3: 436-46. doi: $10.1177 / 1947601912458584$.

4. Druker BJ, Guilhot F, O’Brien SG, Gathmann I, Kantarjian H, Gattermann N, Deininger MW, Silver RT, Goldman JM, Stone RM, Cervantes F, Hochhaus A, Powell BL, et al. Five-year follow-up of patients receiving imatinib for chronic myeloid leukemia. N Engl J Med. 2006; 355: 240817. doi: 10.1056/NEJMoa062867.

5. Baccarani M, Cortes J, Pane F, Niederwieser D, Saglio G, Apperley J, Cervantes F, Deininger M, Gratwohl A, Guilhot F, Hochhaus A, Horowitz M, Hughes T, et al. Chronic myeloid leukemia: an update of concepts and management recommendations of European LeukemiaNet. J Clin Oncol. 2009; 27: 6041-51. doi: 10.1200/JCO.2009.25.0779.

6. Roberts KG, Li Y, Payne-Turner D, Harvey RC, Yang YL, Pei D, McCastlain K, Ding L, Lu C, Song G, Ma J, Becksfort J, Rusch M, et al. Targetable kinase-activating lesions in Ph-like acute lymphoblastic leukemia. N Engl J Med. 2014; 371: 1005-15. doi: 10.1056/NEJMoa1403088.

7. Boer JM, Koenders JE, van der Holt B, Exalto C, Sanders MA, Cornelissen JJ, Valk PJ, den Boer ML, Rijneveld AW. Expression profiling of adult acute lymphoblastic leukemia identifies a BCR-ABL1-like subgroup characterized by high non-response and relapse rates. Haematologica. 2015; 100: e261-4. doi: 10.3324/haematol.2014.117424.
8. de Lavallade H, Apperley JF, Khorashad JS, Milojkovic D, Reid AG, Bua M, Szydlo R, Olavarria E, Kaeda J, Goldman JM, Marin D. Imatinib for newly diagnosed patients with chronic myeloid leukemia: incidence of sustained responses in an intention-to-treat analysis. J Clin Oncol. 2008; 26: 3358-63. doi: 10.1200/JCO.2007.15.8154.

9. Lucas CM, Wang L, Austin GM, Knight K, Watmough SJ, Shwe KH, Dasgupta R, Butt NM, Galvani D, Hoyle $\mathrm{CF}$, Seale JR, Clark RE. A population study of imatinib in chronic myeloid leukaemia demonstrates lower efficacy than in clinical trials. Leukemia. 2008; 22: 1963-6. doi: 10.1038/leu.2008.225.

10. Branford S, Hughes TP. Mutational analysis in chronic myeloid leukemia: when and what to do? Curr Opin Hematol. 2011; 18: 111-6. doi: 10.1097/ MOH.0b013e32834399ef.

11. Bixby D, Talpaz M. Seeking the causes and solutions to imatinib-resistance in chronic myeloid leukemia. Leukemia. 2011; 25: 7-22. doi: 10.1038/leu.2010.238.

12. Apperley JF. Part I: mechanisms of resistance to imatinib in chronic myeloid leukaemia. Lancet Oncol. 2007; 8: 101829. doi: 10.1016/S1470-2045(07)70342-X.

13. White DL, Saunders VA, Dang P, Engler J, Venables A, Zrim S, Zannettino A, Lynch K, Manley PW, Hughes T. Most CML patients who have a suboptimal response to imatinib have low OCT-1 activity: higher doses of imatinib may overcome the negative impact of low OCT-1 activity. Blood. 2007; 110: 4064-72. doi: 10.1182/ blood-2007-06-093617.

14. Carroll M, Ohno-Jones S, Tamura S, Buchdunger E, Zimmermann J, Lydon NB, Gilliland DG, Druker BJ. CGP 57148, a tyrosine kinase inhibitor, inhibits the growth of cells expressing BCR-ABL, TEL-ABL, and TEL-PDGFR fusion proteins. Blood. 1997; 90: 4947-52.

15. Weisberg E, Manley PW, Breitenstein W, Bruggen J, Cowan-Jacob SW, Ray A, Huntly B, Fabbro D, Fendrich G, Hall-Meyers E, Kung AL, Mestan J, Daley GQ, et al. Characterization of AMN107, a selective inhibitor of native and mutant Bcr-Abl. Cancer Cell. 2005; 7: 129-41. doi: 10.1016/j.ccr.2005.01.007.

16. Fiskus W, Pranpat M, Balasis M, Bali P, Estrella V, Kumaraswamy S, Rao R, Rocha K, Herger B, Lee F, Richon V, Bhalla K. Cotreatment with vorinostat (suberoylanilide hydroxamic acid) enhances activity of dasatinib (BMS354825) against imatinib mesylate-sensitive or imatinib mesylate-resistant chronic myelogenous leukemia cells. Clin Cancer Res. 2006; 12: 5869-78. doi: 10.1158/10780432.CCR-06-0980.

17. Redaelli S, Piazza R, Rostagno R, Magistroni V, Perini P, Marega M, Gambacorti-Passerini C, Boschelli F. Activity of bosutinib, dasatinib, and nilotinib against 18 imatinibresistant BCR/ABL mutants. J Clin Oncol. 2009; 27: 469-71. doi: 10.1200/JCO.2008.19.8853.

18. O'Hare T, Shakespeare WC, Zhu X, Eide CA, Rivera VM, Wang F, Adrian LT, Zhou T, Huang WS, Xu Q, Metcalf 
CA, 3rd, Tyner JW, Loriaux MM, et al. AP24534, a panBCR-ABL inhibitor for chronic myeloid leukemia, potently inhibits the T315I mutant and overcomes mutation-based resistance. Cancer Cell. 2009; 16: 401-12. doi: 10.1016/j. ccr.2009.09.028.

19. Zabriskie MS, Eide CA, Tantravahi SK, Vellore NA, Estrada J, Nicolini FE, Khoury HJ, Larson RA, Konopleva M, Cortes JE, Kantarjian H, Jabbour EJ, Kornblau SM, et al. BCR-ABL1 compound mutations combining key kinase domain positions confer clinical resistance to ponatinib in $\mathrm{Ph}$ chromosome-positive leukemia. Cancer Cell. 2014; 26: 428-42. doi: 10.1016/j.ccr.2014.07.006.

20. Daley GQ, Baltimore D. Transformation of an interleukin 3-dependent hematopoietic cell line by the chronic myelogenous leukemia-specific P210bcr/abl protein. Proc Natl Acad Sci U S A. 1988; 85: 9312-6.

21. Warmuth M, Kim S, Gu XJ, Xia G, Adrian F. Ba/F3 cells and their use in kinase drug discovery. Curr Opin Oncol. 2007; 19: 55-60. doi: 10.1097/CCO.0b013e328011a25f.

22. Kumar M, Keller B, Makalou N, Sutton RE. Systematic determination of the packaging limit of lentiviral vectors. Hum Gene Ther. 2001; 12: 1893-905. doi: 10.1089/104303401753153947.

23. al Yacoub N, Romanowska M, Haritonova N, Foerster J. Optimized production and concentration of lentiviral vectors containing large inserts. J Gene Med. 2007; 9: 57984. doi: 10.1002/jgm.1052.

24. Woods NB, Muessig A, Schmidt M, Flygare J, Olsson K, Salmon P, Trono D, von Kalle C, Karlsson S. Lentiviral vector transduction of NOD/SCID repopulating cells results in multiple vector integrations per transduced cell: risk of insertional mutagenesis. Blood. 2003; 101: 1284-9. doi: 10.1182/blood-2002-07-2238.

25. Charrier S, Ferrand M, Zerbato M, Precigout G, Viornery A, Bucher-Laurent S, Benkhelifa-Ziyyat S, Merten OW, Perea J, Galy A. Quantification of lentiviral vector copy numbers in individual hematopoietic colony-forming cells shows vector dose-dependent effects on the frequency and level of transduction. Gene Ther. 2011; 18: 479-87. doi: 10.1038/ gt.2010.163.

26. Shearer RF, Saunders DN. Experimental design for stable genetic manipulation in mammalian cell lines: lentivirus and alternatives. Genes Cells. 2015; 20: 1-10. doi: 10.1111/ gtc. 12183 .

27. Schroder AR, Shinn P, Chen H, Berry C, Ecker JR, Bushman F. HIV-1 integration in the human genome favors active genes and local hotspots. Cell. 2002; 110: 521-9.

28. Gozgit JM, Schrock A, Chen T-H, Clackson T, Rivera VM. Comprehensive Analysis Of The In Vitro Potency Of Ponatinib, and All Other Approved BCR-ABL Tyrosine Kinase Inhibitors (TKIs), Against a Panel Of Single and Compound BCR-ABL Mutants. Blood. 2013; 122: 3992.

29. Eide CA, Zabriskie MS, Adrian LT, Lange T, Deininger MW, Druker BJ, O'Hare T. Resistance Profiling of BCRABL Compound Mutations Linked to Tyrosine Kinase
Inhibitor Therapy Failure in Chronic Myeloid Leukemia. ASH Annual Meeting Abstracts. 2011; 118: 1416.

30. Vigdal TJ, Kaufman CD, Izsvak Z, Voytas DF, Ivics Z. Common physical properties of DNA affecting target site selection of sleeping beauty and other Tc1/mariner transposable elements. J Mol Biol. 2002; 323: 441-52.

31. Xue X, Huang X, Nodland SE, Mates L, Ma L, Izsvak Z, Ivics Z, LeBien TW, McIvor RS, Wagner JE, Zhou $X$. Stable gene transfer and expression in cord bloodderived CD34+ hematopoietic stem and progenitor cells by a hyperactive Sleeping Beauty transposon system. Blood. 2009; 114: 1319-30. doi: 10.1182/ blood-2009-03-210005.

32. Wachter K, Kowarz E, Marschalek R. Functional characterisation of different MLL fusion proteins by using inducible Sleeping Beauty vectors. Cancer Lett. 2014; 352: 196-202. doi: 10.1016/j.canlet.2014.06.016.

33. Emerenciano M, Kowarz E, Karl K, de Almeida Lopes B, Scholz B, Bracharz S, Meyer C, Pombo-de-Oliveira MS, Marschalek R. Functional analysis of the two reciprocal fusion genes MLL-NEBL and NEBL-MLL reveal their oncogenic potential. Cancer Lett. 2013; 332: 30-4. doi: 10.1016/j.canlet.2012.12.023.

34. Schinnerl D, Fortschegger K, Kauer M, Marchante JR, Kofler R, Den Boer ML, Strehl S. The role of the Janus-faced transcription factor PAX5-JAK2 in acute lymphoblastic leukemia. Blood. 2015; 125: 1282-91. doi: 10.1182/blood-2014-04-570960.

35. Kacherovsky N, Harkey MA, Blau CA, Giachelli CM, Pun SH. Combination of Sleeping Beauty transposition and chemically induced dimerization selection for robust production of engineered cells. Nucleic Acids Res. 2012; 40: e85. doi: 10.1093/nar/gks213.

36. Redaelli S, Mologni L, Rostagno R, Piazza R, Magistroni V, Ceccon M, Viltadi M, Flynn D, Gambacorti-Passerini C. Three novel patient-derived BCR/ABL mutants show different sensitivity to second and third generation tyrosine kinase inhibitors. Am J Hematol. 2012; 87: E125-8. doi: 10.1002/ajh.23338.

37. Senechal K, Halpern J, Sawyers CL. The CRKL adaptor protein transforms fibroblasts and functions in transformation by the BCR-ABL oncogene. J Biol Chem. 1996; 271: 23255-61.

38. Sattler M, Salgia R. Role of the adapter protein CRKL in signal transduction of normal hematopoietic and BCR/ ABL-transformed cells. Leukemia. 1998; 12: 637-44.

39. Shah NP, Skaggs BJ, Branford S, Hughes TP, Nicoll JM, Paquette RL, Sawyers CL. Sequential ABL kinase inhibitor therapy selects for compound drug-resistant BCR-ABL mutations with altered oncogenic potency. J Clin Invest. 2007; 117: 2562-9. doi: 10.1172/JCI30890.

40. Kowarz E, Loscher D, Marschalek R. Optimized Sleeping Beauty transposons rapidly generate stable transgenic cell lines. Biotechnol J. 2015; 10: 647-53. doi: 10.1002/ biot.201400821. 
41. Al-Achkar W, Wafa A, Moassass F, Klein E, Liehr T. Multiple copies of BCR-ABL fusion gene on two isodicentric Philadelphia chromosomes in an imatinib mesylate-resistant chronic myeloid leukemia patient. Oncol Lett. 2013; 5: 1579-82. doi: 10.3892/ol.2013.1225.

42. Gorre ME, Mohammed M, Ellwood K, Hsu N, Paquette R, Rao PN, Sawyers CL. Clinical resistance to STI-571 cancer therapy caused by BCR-ABL gene mutation or amplification. Science. 2001; 293: 876-80. doi: 10.1126/science.1062538.

43. Gambacorti-Passerini CB, Gunby RH, Piazza R, Galietta A, Rostagno R, Scapozza L. Molecular mechanisms of resistance to imatinib in Philadelphia-chromosome-positive leukaemias. Lancet Oncol. 2003; 4: 75-85.

44. Yeung DT, Moulton DJ, Heatley SL, Nievergall E, Dang P, Braley J, Branford S, Moore S, Mullighan CG, Hughes TP, White DL. Relapse of BCR-ABL1-like ALL mediated by the ABL1 kinase domain mutation T315I following initial response to dasatinib treatment. Leukemia. 2015; 29: 230-2. doi: 10.1038/leu.2014.256.

45. Mayerhofer M, Gleixner KV, Mayerhofer J, Hoermann G, Jaeger E, Aichberger KJ, Ott RG, Greish K, Nakamura H, Derdak S, Samorapoompichit P, Pickl WF, Sexl V, et al. Targeting of heat shock protein 32 (Hsp32)/heme oxygenase-1 (HO-1) in leukemic cells in chronic myeloid leukemia: a novel approach to overcome resistance against imatinib. Blood. 2008; 111: 2200-10. doi: 10.1182/ blood-2006-11-055723.

46. Konig M, Reichel M, Marschalek R, Haas OA, Strehl $\mathrm{S}$. A highly specific and sensitive fluorescence in situ hybridization assay for the detection of $\mathrm{t}(4 ; 11)(\mathrm{q} 21 ; \mathrm{q} 23)$ and concurrent submicroscopic deletions in acute leukaemias. Br J Haematol. 2002; 116: 758-64. 